Article

\title{
Can Design for the Environment be Worthwhile? Green Design for Manufacturers Brands When Confronted with Competition from Store Brands
}

\author{
Xi Yang ${ }^{1,2, *}$, Maozeng $X u^{1}$ and Wanleng Zhang ${ }^{3, *(1)}$ \\ 1 School of Economics and Management, Chongqing Jiaotong University, Chongqing 400074, China; \\ xmzzrxhy@cqjtu.edu.cn \\ 2 School of Economics and Management, Southwest University of Institute and Technology, \\ Mianyang 621010, China \\ 3 School of Management and Economics, University of Electronic Science and Technology of China, \\ Chengdu 611731, China \\ * Correspondence: 611140120003@mails.cqjtu.edu.cn (X.Y.); 2017110902022@std.uestc.edu.cn (W.Z.)
}

Received: 31 December 2019; Accepted: 30 January 2020; Published: 3 February 2020

\begin{abstract}
To contribute to global sustainability, many manufacturers are starting to implement green product development and trying to provide environmentally friendly products. Although green products are environmentally beneficial to our society, the performance of green product development remains poor because of cannibalization from traditional alternatives at lower prices. This is particularly the case in the current unforgiving marketing reality in which many brand retailers, such as Wal-Mart, Tesco, and Carrefour, offer their own store brands as traditional alternatives. Although a large stream of research has studied the effects of competition on manufacturers' green design, to the best of our knowledge, there is a dearth of research on the effects of competition from retailers' store brands on manufacturers' green design. To fill this gap, we present two models in which the manufacturer has an incentive to design for the environment, and the retailer has the flexibility to sell store brands (Model S), or it does not (Model N). Surprisingly, our analysis indicates that the presence of store brands may stimulate the manufacturer to release a new greener version of the national brand. Moreover, we find that although the presence of store brands is beneficial to the retailer and industry, it always hurts the manufacturer's profitability. To incentivize the manufacturer to support Model S, we propose a two-part tariff contract.
\end{abstract}

Keywords: green design; innovation; national brands; store brands; game theory

\section{Introduction}

To achieve sustainable development in both economic and environmental contexts, many governments and environmental groups are sparing no effort to encourage consumers to buy "green" products that are "low-carbon", "renewable", "energy-efficient", and "ecologically friendly". For example, in 1972, the US established the first United Nations Environment Program, with the aim to protect the planet from potential pollution. This tendency is particular noticeable in last decades: The US Environmental Protection Agency provides a national marginal emissions factor for the greenhouse gases equivalencies calculator for daily consumption and intends to encourage public engagement in green lifestyle [1].

It should be noted that the parameters for lifestyle indicates a stronger effect of changes on the probability that a respondent opts for products purchasing [2]. As a result of the above efforts for encouraging consumers to buy "green" products, consumers are increasingly paying more attention to the "green" attributes of products to minimize the potential negative impacts during their whole 
life cycle. In particular, as the green movements become more prevalent, more and more consumers eventually change their purchase behaviors and become more receptive to green products [3]. The report by Eurobarometer [4] showed that more than $75 \%$ of respondents would preferentially purchase environmentally friendly products over traditional products. Similarly, a survey conducted by the State Environment Protection Administration asserted that $78.8 \%$ of consumers in the Chinese market would also be willing to buy environmentally friendly products [5].

On the other hand, from the enterprise perspective, sustainability is a key driver of innovation. Increasingly, sustainable management is being regarded as an opportunity for innovation, and not as a threat to a company [6]. More specifically, to cater the "green" lifestyle, many manufacturers are building a new manufacturing service innovation system with "Design-for-environment", in which "environmental considerations are integrated into product and process engineering design procedures" [7], and starting to make environmentally friendly products availed from their retail outlets [8]. For example, to contribute to global environmental protection and remain competitive, since 1996, Nike has offered green products by manufacturing a range of clothing and footwear products made from green materials such as organic cotton, and it has been a global leader in organic cotton use since 2005. The situation is especially serious in the vehicle industry. Chevrolet announced that it would provide the S-10 electric pickup truck, which is considered much more environmentally friendly than other models that use conventional combustion engines and fuels [9]. In the US market, the proportion of green products accounted for new product introductions around 1\% in 1986 to above $13 \%$ in 1991 [10]. A variety of green products can be found in various industries, such as electric vehicles, non-phosphate laundry powder, and solar water heaters [11]. As suggested by Business Week's Janet Ginsburg, "If US companies want to stay competitive, they may want to start thinking green sooner rather than later" [12].

Of course, green preferences are not the only factor the customers consider when they make a purchase [8]. In practice, many consumers may press for increased green attributes, while others would demand low prices [13]. The top challenge for manufacturers of green products is the higher price compared with traditional products due to costs associated with the investment in research and development [13]. This is known as green product differentiation [14]. For example, in 2005, Nike's green products contributed to a reduction of approximately 4.3 million pounds of consumed petrochemical raw materials, but these products are more expensive than those made of polyester [15]. Typically, if a firm charges higher prices for green products, they face the problem of potential cannibalization from traditional types of products, resulting in the erosion of profits obtained from green product development [16].

The cannibalization problem is particularly noticeable in the current unforgiving marketing reality, in which many brand retailers offer their own store brands that compete directly with manufacturer brands [2,17]. In practice, many brand retailers developed a low-price strategy for their "generic" brands that enabled them to compete with manufacturer brands [18]. Since 2017, Wal-Mart has offered store brands, such as Great Value, Mainstays, and Faded Glory. Drivers of the market share of retailers' store brands have been attributed to the lower price of alternatives available to the consumer [19]. Such a low-price strategy enables store brands to have experienced considerable growth in the last three decades, often at the expense of national brands [20-22]. According to PLMA's 2015 Yearbooks, the market share of store brands will increase significantly and reach 115.3 billion dollars in the next few years [23]. Undoubtedly, if manufacturers intend to design for the environment with a price premium, the days of ignoring cannibalization problems from retailers' store brands are over because "boosting prices further could drive consumers to buy even more private-label goods (retailer store bands), reducing the companies' sales volume and squeezing their profit margins at the factory level by raising the cost of production per unit" [24].

Although a large stream of research has studied the effect of competition on manufacturers' green design (see, e.g., [25] and references therein), to the best of our knowledge, there is a dearth of research on the effects of competition from retailers' store brands on manufacturers' green design. Furthermore, 
although retailers' store brands can cannibalize manufacturers' national brands (see, e.g., [17] and references therein), little attention has been paid to the effects of retailers' store brands on manufacturers' green product development. There is an urgent need for more research on sustainable practices through the lenses of different sectoral innovation systems, new business model perspectives, technological, organizational, and social practices [6]. Therefore, to fill this gap, we present two theoretical models to analyze the problem of confronting competition from retailers' store brands: Can a manufacturer benefit from design for the environment?

Motivated by this fundamental research question, we present two models in which the manufacturer has an incentive to design for the environment, and the retailer has the flexibility to sell store brands (Model S), or it does not (Model N). Using these two models, we intend to answer the following research questions:

(1) How do the retailer's store brands affect both parties' optimal strategies?

(2) How do the retailer's store brands affect the manufacturer's incentives for green design?

(3) How do the retailer's store brands affect the profitability of the respective parties?

We find that although the retailer may distribute greater quantities of the national brands, the presence of store brands squeezes the manufacturer's margins. As regards the manufacturer's incentives for green design, our analysis reveals that, contrary to popular belief, the presence of store brands may actually stimulate the manufacturer to release a new greener version of the national brand. Moreover, we further find that although the presence of store brands is beneficial to the retailer and industry, it always hurts the manufacturer's profitability. Finally, to incentivize the manufacturer to support Model S, we propose a two-part tariff contract.

Our article is organized as follows. We first review the related literature in Section 2 and introduce the model formulation, and demonstrate the equilibriums of both models in Section 3. We then highlight the differences between the optimal strategies of the two models in Section 4. Finally, we conclude the paper in Section 5.

\section{Literature Review}

The first stream related to this paper is green product design, that begin with the consumers' preferences. For example, Pritchard and Wilson [26] examined consumer responses to new green products and their impact on a parent firm's corporate reputation. They showed that adding a new green product to a service company's portfolio can improve consumer perceptions of corporate reputation. Wang et al. [27] examined the antecedents, consequences, and moderators of fairness perceptions in consumer responses to the offering of green services, and their results revealed that consumers' inference of the firm's relative profit negatively influences their perceived fairness. Recently, Chen et al. [28] indicated that the improvement of firms' economic performance resulting from $R \& D$ cooperation is mainly determined by firms' own level of green contribution. In addition, Laroche et al. [29], Morrison and Beer [30], and Kai and Deng [31] provided empirical support for the growing environmental consciousness of consumers. In this paper, following the empirical evidence and theoretical results in these previous papers, we also treat green product design as an important means that is affected by the consumers' preferences, but our approach differs in an important way: After the store brand product is introduced, consumers have the flexibility to choose alternatives offered by the retailer that are less expensive than the green products provided the manufacturer.

Another stream of research related to this paper is the innovation and competitiveness. In particular, Yang et al. [8], considering the fuzziness of the correlation between indicators for innovation performance in enterprise and consumer's green preferences, used a fuzzy clustering method to identify the internal relations among the indicators for innovation performance with green preferences of customers. Wright et al. [13] integrated new product development and environmental management philosophies in order to develop and empirically test a theoretical framework for environmental new product development and performance. Meanwhile, Anning-Dorson [32] investigated how service firms 
across two different cultural contexts use their customer involvement capabilities to create competitive advantage. Chen [33] developed a quality-based model for the optimal choice of green level when confronted with conflicting traditional attributes. Similarly, Zhang et al. [34] assumed to produce two types of products - environmental and traditional products - which differed in price and environmental quality. Their results showed that the difference between the two products determines the order quantity of the traditional product. We refer the reader to Du et al. [25] for a comprehensive literature review of the competition between green and traditional products. As mentioned earlier, although a large stream of research has studied the manufacturer's green innovation in the face of competition, to the best of our knowledge, there is a dearth of research on whether a manufacturer should design for the environment when confronted with competition from the store brands.

The introduction of store brands, particularly those that result in competition between the national brand and the store brand, is also an important issue that is relevant to this paper. For example, Mieres et al. [20] analyzed the relationship between different aspects related to the purchasing behavior of consumers and the difference in perceived risk between store brands and national brands. Similarly, Steenkamp et al. [17], using consumer survey data from 22,623 respondents from 23 countries in Asia, Europe, and across the Americas (with an average of 63 categories of consumer packaged goods per country), studied the effects of marketing and manufacturing factors on the price premium that a consumer is willing to pay for a national brand over a store brand. Gómez [35] studied the rationale for producing store brands and the possible existence of different segments of store brand manufacturers according to their competitive position, size, advertising investment, sector concentration, and type of product. Subsequently, Ailawadi et al. [36] showed that the share of a retailer's store brands significantly affects the three measures of behavioral loyalty: Share of wallet, share of items purchased, and share of shopping trips. Recently, Rubio et al. [37], the authors revealed a negative effect of the inference of brand awareness-brand quality on the consumer's identification with store brands as a result of the greater functional risk perceived for these brands. Although numerous researchers have addressed the competition between the national brand and the store brand, our aim and model settings are quite different. For example, collectively, the above papers do not address the effects of store brands on a manufacturer's product development outputs, which is a fundamental focus of our models so that we can investigate the competition effects of store brands on a manufacturer's design for the environment.

\section{Assumptions}

We consider two theoretical models: The basic model (see Model B in Figure 1), in which the retailer does not offer store brands, and Model S in Figure 1, in which the retailer can distribute its own store brands as well as the national brands wholesaled by the manufacturer. The sequence of both models is as follows. First, the manufacturer decides whether to introduce a greener version of a national brand. Then, it announces the wholesale prices to a retailer, which responds by determining the optimal quantities of the national brand and the store brand.

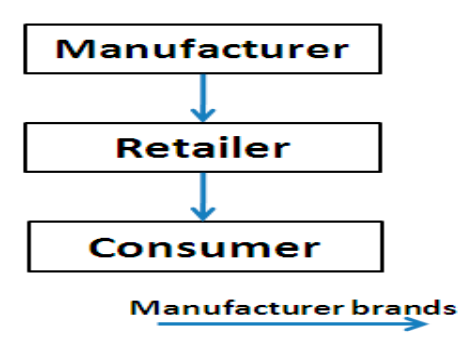

(a) Model B

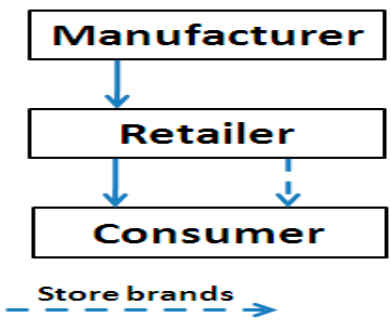

(b) Models

Figure 1. Scenarios modeled and analyzed in this paper. 
Suppose that all consumers' willingness to pay for a national brand is $v$, which is uniformly distributed on the interval $[0,1]$; that is, $v \sim U[0,1][38]$. To reflect the fact that the consumer preferentially purchases environmentally friendly products, as in Guo et al. [15], Chen et al. [28], and Agrawal and Uelkue [39], we assume that if a new greener version of the national brand is introduced, then consumers' willingness to pay increases by a factor $\sigma_{1}=1+a$, where $a$ represents the level of environmental friendliness of the new greener version of the national brand. Thus, following Yin et al. [38] and Agrawal and Uelkue [39], we can obtain the consumer utility function for the new greener version of the national brand by solving $U_{n}=\sigma_{1} v-p_{n}$, where $p_{n}$ refers to the price of the new greener version of the national brand.

On the other hand, to reflect the cannibalization effect from the retailer's store brands, as in Liu et al. [19] and Mieres et al. [20], we assume that store brands are usually perceived as alternatives whose quality and awareness are inferior to those of national brands. That is, to model this difference between the store and national brands, following prior researches, we let $\sigma_{2} \in[0,1]$ refer to the degree of substitution of the retailer's store brands to the manufacturer's national brands. Therefore, the consumer utility function for the retailer's store brand is $U_{s}=\sigma_{2} v-p_{s}$, where $p_{s}$ refers to the price of the new greener version of the national brand.

Using the consumer utility functions for the manufacturer's national brand and the retailer's store brand, we can rewrite the demands for both products as follows.

$$
\begin{gathered}
p_{n}=\sigma_{1}\left(1-q_{n}\right)-\sigma_{2} q_{s} \\
p_{s}=\sigma_{2}\left(1-q_{n}-q_{s}\right)
\end{gathered}
$$

Typically, the core of design for the environment comprises new technologies that still need R\&D investment [33]. Therefore, consistent with prior literature on R\&D (see, e.g., Yin et al. [38], Qian et al. [40], and Yan et al. [41]), we assume that the cost of product development is a quadratic function of the designed green level, i.e., $c_{d}=\frac{k\left(\sigma_{1}^{2}-1\right)}{2}$.

This formulation implies the following two important characteristics related to product development. First, there is a threshold value $k$ that represents the cost below which the manufacturer will engage in design for the environment and release a greener version of the national brand [38]. Second, if the manufacturer does not introduce a greener version of the national brand, then there is no product development cost (that is, as $a \rightarrow 0, c_{d} \rightarrow 0$ ).

Our model thus reflects several key characteristics on the competition between the manufacturer brands and store brands: First, to be consistent with the fact that the manufacturer's national brand is a product manufactured by the manufacturer but sold by the retailer, we assume that, in our both models, all manufacturer brands are wholesaled to the retailer, who then resale them to the consumer market. Second, to model the store brands that would be close substitutes to national brand products, we let $\sigma_{2} \in[0,1]$ refer to the degree of substitution of the retailer's store brands to the manufacturer's national brands. In addition, because both national and store brands are sold by the retailer, without loss of generality, we assume that the marginal selling costs for national and store brands are $c_{n}$ and $c_{S}$, respectively.

\section{Model Formulation and Solution}

In the following analysis, the superscript $i \in\{B, S\}$ refers to Model B and Model S, respectively, while the subscript $j \in\{m, r\}$ represents the manufacturer and the retailer, respectively. 


\subsection{Model B}

As a benchmark, see Figure 1a, we first focus on Model B, in which the retailer does not offer store brands but resells all national brands from the manufacturer. Therefore, based on Equation (1), we can rewrite the inverse demand functions under Model B as follows:

$$
p_{n}=\sigma_{1}\left(1-q_{n}\right)
$$

Recalled that, in the first stage, the manufacturer decides whether to introduce a greener version of a national brand and announces the wholesale prices to the retailer, who responds by determining the optimal quantities of the store brands. We use backward induction to solve Model B. Accordingly, under Model B, the retailer's problem is choosing the optimal number of units of national brands $\left(q_{n}\right)$ to maximize its profits. Then, the retailer's profit under Model B is

$$
\max _{q_{n}} \pi_{r}^{B}=\left(p_{n}-c_{n}\right) q_{n}-w_{n} q_{n}
$$

Note that $c_{n}$ is the unit selling cost of the national brands, while $w_{n}$ is the wholesale price paid to the manufacturer.

Anticipating the retailer's optimal response in (3), the manufacturer sets its optimal wholesale price to maximize its profits:

$$
\max _{w_{n}} \pi_{m}^{B}=w_{n} q_{n}-\frac{k\left(\sigma_{1}^{2}-1\right)}{2}
$$

where the first term is the manufacturer's revenue from product wholesale, while the second term is the product development cost of green product design.

Obviously, the manufacturer's decision to introduce a greener version depends on whether the extra revenue from design for the environment, i.e., $w_{n} q_{n}$, is more than the cost of doing so, i.e., $\frac{k\left(\sigma_{1}^{2}-1\right)}{2}$. To analyze the OEM's incentives for designing for the environment, we need to compare the OEM's profit under the scenario in which it engages in design for the environment with that in which it releases the existing versions. This comparison leads to a threshold $K^{B}$, below which the OEM releases a greener version.

Using backward induction, we can determine the subgame perfect equilibrium. We first solve the first-order condition of (3), which yields $q_{n}^{B *}$, and then substitute it into (4) and maximize this function with $w_{n}^{B *}$. We summarize the equilibrium decisions of Model B in Table 1 (Derivation of the optimal decisions are provided in Appendix A).

\subsection{Model S}

In Model S, see Figure 1b, the manufacturer wholesales the national brands to the retailer, which then distributes them while also providing its own store brands. Given the inverse demand in (1), the retailer's objective is to determine the optimal number of units of national brands $\left(q_{n}\right)$ and store brands $\left(q_{s}\right)$ to maximize its profits:

$$
\max _{q_{n}, q_{s}} \pi_{r}^{S}=\left(p_{n}-c_{n}\right) q_{n}+\left(p_{s}-c_{S}\right) q_{s}-w_{n} q_{n}
$$

Recalled that, in Model S, the manufacturer first decides whether to introduce a greener version of a national brand. Then, it announces the wholesale prices to the retailer, who responds by determining the optimal quantities of the national brand and the store brand. We again use backward induction 
to solve Model S. That is, anticipating the retail's above optimal response, the manufacturer sets its optimal wholesale price to maximize its profits:

$$
\max _{w_{n}} \pi_{m}^{S}=w_{n} q_{n}-\frac{k\left(\sigma_{1}^{2}-1\right)}{2}
$$

Maximizing the retailer's profits in (5) obtains $q_{n}^{S *}$ and $q_{s}^{S *}$, and substituting them into (6) provides the optimal $w_{n}^{S_{*}^{*}}$. We summarize the equilibrium decisions of Model S in Table 1.

Table 1. Equilibrium outcomes for both models.

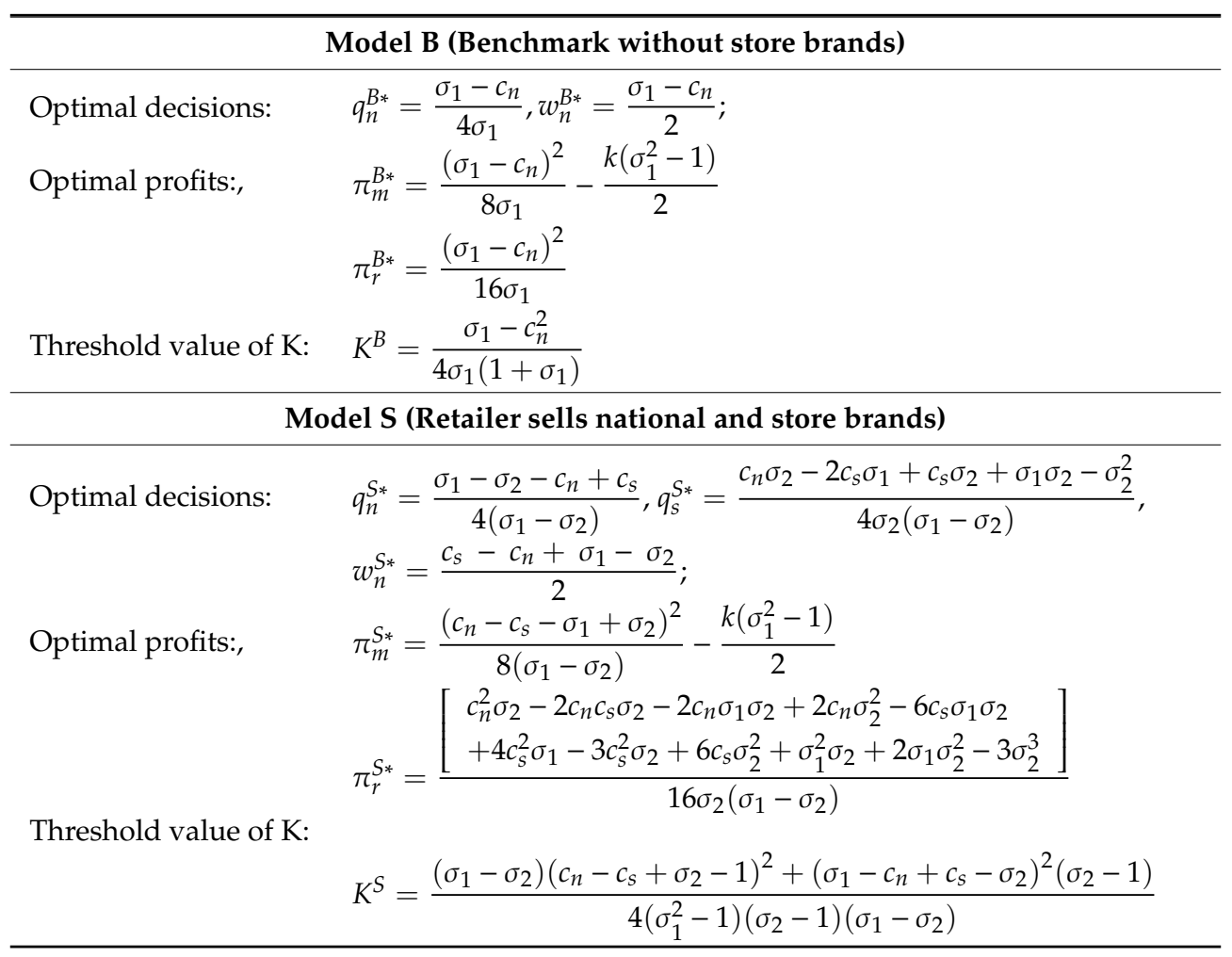

\section{Model Analysis}

In this section, we strive to highlight the difference between the two models and address the several fundamental research questions that are posed at the beginning of this paper. Note that ensure all parameters and variables in this paper must satisfy non-negativity constraints, we need $c_{n}-\sigma_{1}+\sigma_{2}=\underline{c}_{s}<c_{s}<\bar{c}_{s}=\frac{\sigma_{2}\left(c_{n}+\sigma_{1}-\sigma_{2}\right)}{2 \sigma_{1}-\sigma_{2}}$.

\subsection{Comparing Optimal Strategies}

We now analyze the first question posed at the beginning of this paper: How do the retailer's store brands affect both parties' optimal strategies? We first answer this question from the optimal wholesale prices set by the manufacturer (All proofs are provided in Appendix B):

Proposition 1. The manufacturer always sets a lower wholesale price in Model S than that in Model B, i.e., $w_{n}^{S^{*}}<w_{n}^{B^{*}}$

Proposition 1 indicates that the presence of store brands induces the manufacturer to set a lower wholesale price for its national brands. It should be noted that, in Model S, the manufacturer is the monopolistic supplier for the retailer; thus, under this scenario, the manufacturer has an incentive 
to charge monopoly prices for national-brand products. However, in Model S, the retailer has the flexibility to distribute its own store brands. Confronted with competition from the retailer's store brands, the manufacturer decreases wholesale prices to ensure that the retailer does not unduly reduce the demand for the national brands.

On the basis of the relatively powerful sales data of retailers, the authors of extant empirical studies (e.g., Mieres et al. [20], Steenkamp et al. [17], and Sayman et al. [42]) seem to agree that the presence of store brands forces the manufacturer to lower wholesale prices of national brands. However, Proposition 1 further shows that even if the manufacturer is given the flexibility to design for the environment, the introduction of store brands indeed forces the manufacturer to set a lower wholesale price for its national brands.

One may expect the retailer to decrease the quantities of national brands because its own store brands are available in the same market. In fact, this expectation is not always true. In particular,

Proposition 2. If $c_{s}>c_{s 1}$, then the retailer will distribute greater quantities of national brands, i.e., $q_{n}^{S *}>q_{n}^{B *}$, even though its own store brands are also available.

Proposition 2 can be interpreted as follows. It should be noted that, in Model S, there are two main profit sources for the retailer: Selling its own store brands and distributing national brands from the manufacturer. Thus, if the retail cost of store brands is not pronounced, i.e., $c_{S}<c_{s 1}$ (meaning that the marginal profit of selling the store brand will be higher than that of distributing the national brand), then the retailer will reduce the quantities of national brands. However, when the retail cost of store brands is pronounced, i.e., $c_{s}>c_{s 1}$, distributing the national brands is more profitable than selling store brands. Hence, when $c_{s}>c_{s 1}$, the retailer will increase the quantities of national brands.

Extant research (see, e.g., Liu et al. [19], Mieres et al. [20], and Amrouche and Yan, [43]) has found that the introduction of store brands necessarily squeezes the market share of national brands. However, our analysis shows that this is not always true, because distributing national brands can also be beneficial to the retailer through demand expansion or price discrimination. The above intuition follows immediately from a comparison of the inverse demand functions in (1) with those in (2). It is also of interest to distinguish Proposition 2 in this paper from that in [44], which aimed to assess whether the manufacturer can use a sequence in which advertising and pricing decisions are made to alter the strategic effects of a store brand introduced by the retailer.

To better illustrate Proposition 2, we now compare the difference between both models in numerical experiments (Consistent with prior literature, e.g., Zhang et al. [34] and Ru et al. [45], the parameters of the level of environmental friendliness of the new greener version of the national brand and the consumer value discount for store brands are characterized by $a=0.2$ and $\sigma_{2}=0.87$, respectively.). Based on Figure 2, we find that there is a threshold of $c_{s 1}$, above which the retailer would distribute greater quantities of national brands. That is, if the selling cost for store brands is pronounced, i.e., $c_{s}>c_{s 1}$, the difference between the optimal number of units of national products in Model $\mathrm{S}$ is always greater than that in Model B, i.e., $q_{n}^{S_{*}^{*}}-q_{n}^{B_{*}^{*}}>0$; otherwise, $q_{n}^{S_{*}^{*}}-q_{n}^{B_{*}}<0$. 


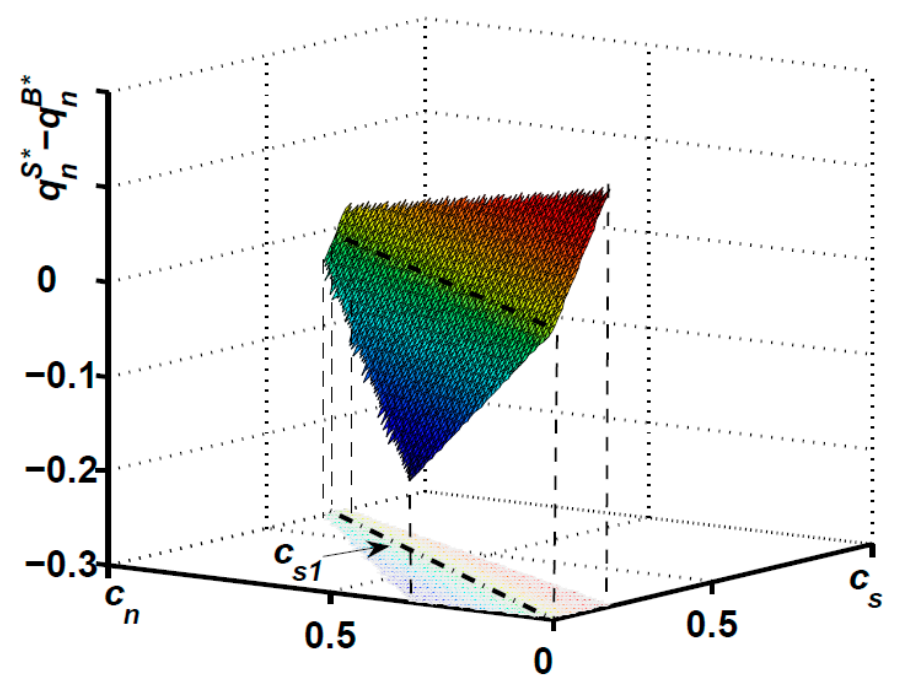

Figure 2. Variations of $q_{n}^{S *}-q_{n}^{B *}$.

\subsection{Comparing Incentives for Green Design}

In this subsection, we analyze the difference in the incentive to design for the environment under Model B and Model S. In other words, we aim to answer the second question posed at the beginning about the effect of the retailer's store brands on the manufacturer's incentives for green product development.

Proposition 3. If $c_{s}>c_{s 2}$, then the presence of store brands stimulates the manufacturer to engage in design for the environment, i.e., $K^{S}>K^{B}$; otherwise, the opposite is true.

Proposition 3 reveals that the presence of store brands may result in higher incentives for green design. We note that if a new greener version of the national brand is introduced, then consumers' willingness to pay increases by a factor of $\sigma_{1}=1+a$, where $a$ represents the level of environmental friendliness of the new greener version of the national brand. The increased willingness to pay increases the marginal revenue from selling greener products. Thus, as Figure 3 shows, when the retail cost of store brands is pronounced, i.e., $c_{s}>c_{s 2}$, the competition from store brands is not high, and the manufacturer has higher incentives to design for the environment, since this increases the incremental profits from innovation and encourages it to "escape" the competition from the store brands. However, when $c_{s}<c_{s 2}$, the competition from store brands is too fierce, and the retailer reduces the quantities of national brands, thereby forcing the manufacturer to decrease the incentives for green design in Model S.

A related issue is the effect of competition on the manufacturer's design for the environment. In particular, Atasu et al. [46] addressed demand-related issues, such as the existence of green segments and original equipment manufacturer competition, and showed that there exists a green segment in the competitive market that allows the manufacturer to defend its market share through price discrimination. However, as mentioned earlier, the previous paper does not assess whether a manufacturer should design for the environment under competition from the retailer's store brand, which is a fundamental focus of our paper. Moreover, the competitive structures in their paper are quite different. They only highlighted the horizontal competition between the manufacturer and its competitors, whereas, in Model S, the manufacturer is both a wholesaler and competitor of the retailer. Thus, we consider both horizontal and vertical competition. 


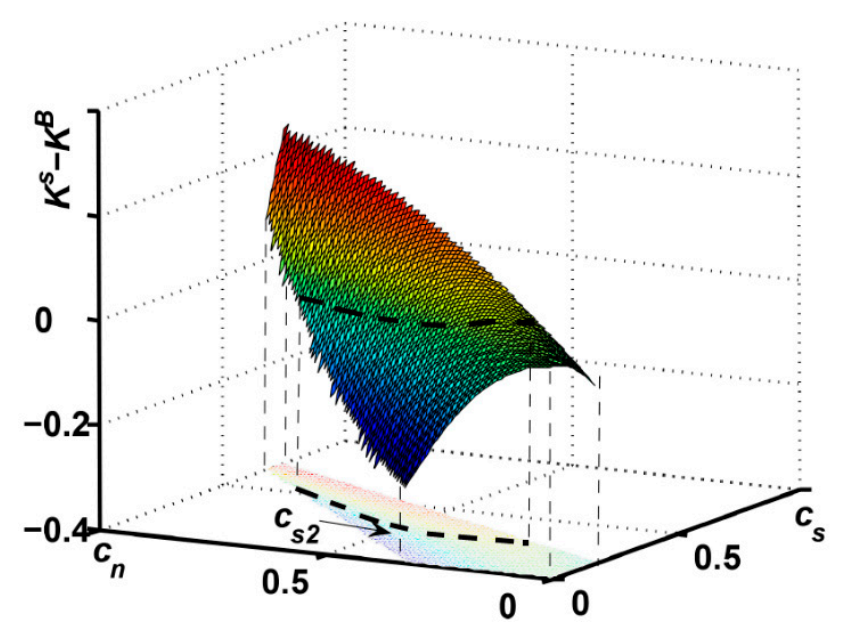

Figure 3. Variations of $K^{S *}-K^{B *}$.

\subsection{Comparing Economic Performance}

A natural question is, "How do the retailer's store brands affect the manufacturer's profitability?" To answer this, we need to compare the manufacturer's profits in Model S with those in Model B. We summarize our results in this subsection (see, Figure 4).

Proposition 4. The presence of store brands always hurts the manufacturer, i.e., $\pi_{m}^{S}<\pi_{m}^{B}$.

The implication of Proposition 4 is as follows. There are two counteracting effects on the manufacturer's profitability in Model S: Any increase in incentives for the greener design of national brands exerts upward pressure, while competition from store brands exerts downward pressure. The introduction of a greener version of the national brand increases the retail price charged to the consumers because their willingness to pay for the national brand increases; however, in Model S, introducing the greener version does not allow the manufacturer to charge a higher wholesale price, and also incurs more investment costs. Consequently, although competition from store brands may result in higher incentives for green design (see Proposition 3) relative to the scenario without store brands, i.e., Model B, the higher investment costs reverse the effect. Moreover, the introduction of store brands decreases wholesale prices (see Proposition 1), and the retailer may also sell more store products in Model S (see Proposition 2). Overall, the presence of store brands is always detrimental to the manufacturer.

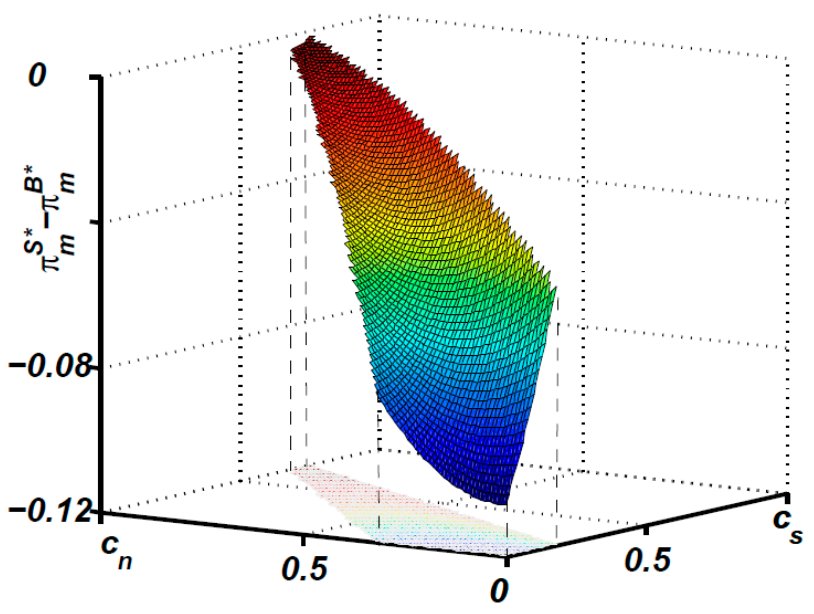

Figure 4. Variations of $\pi_{m}^{S *}-\pi_{m}^{B *}$. 
As regards the effect of the retailer's store brands on the retailer's profitability, from the outcomes in Table 1, see Figure 5, we offer the following proposition.

Proposition 5. The presence of store brands is always beneficial to the retailer, i.e., $\pi_{r}^{S}>\pi_{r}^{B}$.

The rationale for Proposition 5 is as follows. The introduction of store brands not only causes the retailer to obtain additional profits, but also results in the manufacturer losing its position as a monopoly supplier. In particular, when store brands are added, the manufacturer decreases wholesale prices to satisfy the retailer, but the latter is still the monopoly retailer for consumers. Hence, compared with the distribution of national brands only (Model B), the retailer benefits more from the introduction of store brands, that is, $\pi_{r}^{S}>\pi_{r}^{B}$.

Proposition 5 reveals that the retailer always benefits from the introduction of store brands. This is consistent with the fact that mass retailers frequently decide to offer their own store brands to consumers. In 2000, store brands accounted for $20 \%$ of retail sales in the US market. This tendency has become particularly notable since 2007: The growth rate of store brands was $21 \%$, and created more than $\$ 10.5$ billion per year in annual sales [45]. In 2015, the total annual sales of store brands reached $\$ 118.4$ billion in the USA market [47]; this tendency is more prevalent in Europe, in which store brands in large market shares vary between $40 \%$ and $53 \%$ [45].

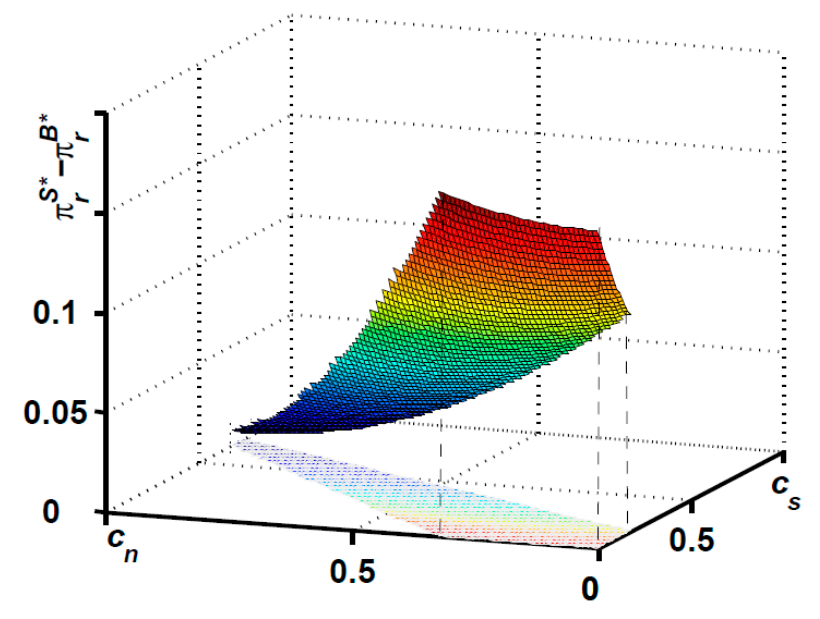

Figure 5. Variations of $\pi_{r}^{S *}-\pi_{r}^{B *}$.

The preceding analysis demonstrates that the presence of store brands is beneficial to the retailer, but detrimental to the manufacturer. We are now in a position to examine the question, "How do the retailer's store brands affect the industry's performance?" From Figure 6, we offer the following proposition.

Proposition 6. The presence of store brands is always beneficial to the industry, i.e., $\pi_{t}^{S}>\pi_{t}^{B}$.

Of course, the introduction of store brands can increase industry profits even when it hurts the manufacturer's profits. Put differently, the retailer's profit "benefits" are sufficient to "compensate" for the manufacturer's profit "loss". More specifically, the presence of store brands is beneficial to the industry because of the following two key factors. On the one hand, the introduction of store brands creates additional profits for retailers. On the other hand, the introduction of store brands mitigates the adverse effects of double marginalization.

Through the above analyses, we have addressed all the research questions posed at the beginning of this paper. In particular, our analysis reveals that the presence of store brands is always beneficial to the retailer and industry (see Propositions 5 and 6), but always leaves the manufacturer in a worse position (see Proposition 4). This discordance in economic objectives implies that managers should 
take the manufacturer's profit "loss" into consideration and coordinate between the contracts of both parties.

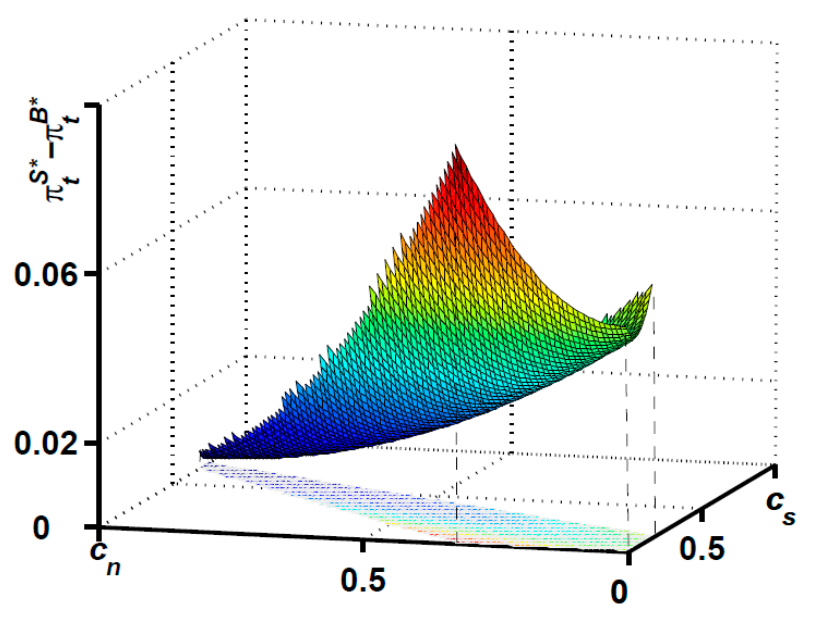

Figure 6. Variations of $\pi_{t}^{S *}-\pi_{t}^{B *}$.

\subsection{Coordination of the Revenue-Sharing Contract}

It should be noted that, to incentivize the manufacturer to support Model S, the results of contracts, such as the two-part tariff contract, revenue-sharing contract, and quantity discount contract, are similar to each other [48]. For simplicity, we propose a two-part tariff contract, which is widely used in green supply chain management $[49,50]$.

Suppose that the manufacturer offers a two-part tariff contract of $\left\{w_{n}, T\right\}$ in Model S, where $w_{n}$ refers to the optimal wholesale price of national brands, and $T$ is a fixed fee that is charged by the retailer. Similar to the analysis in Section 4.2, we can rewrite the retailer's problem as follows.

$$
\max _{q_{n}, q_{s}} \pi_{r}^{S}=\left(p_{n}-c_{n}\right) q_{n}+\left(p_{s}-c_{s}\right) q_{s}-w_{n} q_{n}-T
$$

Given the retailer's optimal responses, the manufacturer aims to maximize its profits by choosing the optimal $\left\{w_{n}, T\right\}$; that is,

$$
\begin{gathered}
\max _{w_{n}, T} \pi_{m}^{S}=w_{n} q_{n}-\frac{k\left(\sigma_{1}^{2}-1\right)}{2}+T \\
\left(p_{n}-c_{n}\right) q_{n}^{*}+\left(p_{s}-c_{s}\right) q_{s}^{*}-w_{n} q_{n}^{*}-T>\pi_{r}^{S *}
\end{gathered}
$$

where $q_{n}^{*}$ and $q_{s}^{*}$ are the optimal quantities of national brands and store brands. Equation (9) is a constraint that ensures that the retailer accepts the coordination contract offered by the manufacturer. We summarize the optimal decisions related to the two-part tariff contract as follows.

Proposition 7. Both the manufacturer and the retailer will prefer Model S if the manufacturer provides a two-part tariff contract with a fixed fee of $T^{S *}=\bar{T}$.

Our findings indicate that if the manufacturer acts as the Stackelberg leader and sponsor of the coordination contract, then the manufacturer extracts all the incremental profits and also ensures that the retailer's profit in Model S is not less than that in Model B. That is, the retailer still prefers to choose Model S when the sharing parameter $T^{S *} \leq \bar{T}$.

Of course, with other conditions remaining the same, if the retailer serves as the sponsor of the coordination contract, then the retailer extracts all the incremental profits and also ensures that the manufacturer's profit in Model S is not less than that in Model B. 


\section{Conclusions, Implications, and Future Research Opportunities}

To cater to the awareness of global environmental protection and remain competitive, many manufacturers are starting to implement green product development and trying to provide environmentally friendly products. These green products are usually accompanied by a higher price compared with traditional products due to costs associated with the investment in research and development. This is known as green product differentiation. However, green preferences is not the only factor the customers consider when they purchase a product. In practice, many consumers may press for increased green attributes, while others would demand low prices. Obviously, although green products provide great environmental benefits to our society, the sales of green product are usually cannibalized by those products with low-prices. This cannibalization problem is particularly noticeable in the current unforgiving marketing reality in which many brand retailers offer their own store brands that compete directly with manufacturer brands: Many brand retailers developed a low-price strategy for their "generic" brands that enabled them to compete with manufacturer brands. In practice, such a low-price strategy enables store brands to have experienced considerable growth in the last three decades, often at the expense of national brands.

Although a large stream of research has studied the effect of substitutions from competitors on manufacturers' green design (see, e.g., Du et al. [25] and references therein), to the best of our knowledge, little attention has been paid to whether a manufacturer should design for the environment when confronting the competition from a retailer's store brand. Motivated by the above fundamental research question, we present two models in which the manufacturer has an incentive for designing for the environment, and a retailer has the flexibility to sell store brands (Model S), or it does not (Model $\mathrm{N})$. Using these two models, we intend to answer the following research questions:

(1) How do the retailer's store brands affect both parties' optimal strategies?

(2) How do the retailer's store brands affect the manufacturer's incentives for green product development?

(3) How do the retailer's store brands affect the profitability of the respective parties?

\subsection{Managerial and Theoretical Implications}

We derive some interesting insights into the green product development of the manufacturer confronted with the retailer's store brand.

First, from the implications on optimal strategies, we can conclude that, confronted with competition from the retailer's store brands, the manufacturer decreases wholesale prices to ensure that the retailer does not unduly reduce the demand for the national brands. This may consistent with the fact that store brands force the manufacturers to lower the wholesale prices of their national products. An argument is empirically supported by (e.g., Mieres et al. [20], Steenkamp et al. [17], and Sayman et al. [42]). On the other hand, our results indicate that, if the retail cost of store brands is not pronounced, i.e., $c_{s}<c_{s 1}$, then the retailer will reduce the quantities of national brands. However, when the retail cost of store brands is pronounced, i.e., $c_{s}>c_{s 1}$, distributing the national brands is more profitable than selling store brands. This theoretical argument seems to agree that the introduction of a store brand may not necessarily cannibalize the demands for the manufacturer brands, because a rational retailer would maximize its profit from selling store brands and reselling manufacturer brands. In particular, when manufacturers are building a new manufacturing service innovation system with "Design-for-environment", the retailer should look for ways to combine low cost and products differentiation.

Second, from the implications on incentives for green design, our analysis reveals that, when the retail cost of store brands is pronounced, i.e., $c_{s}>c_{s 2}$, the introduction of store brand stimulates the manufacturer to lease a "greener" version. The manufacturer has higher incentives to design for the environment since this increases the incremental profits from innovation and encourages it to "escape" the competition from the store brands. This is consistent with the argument in Arrow [51], who posits that an innovator is likely to protect their property rights by further innovation, as this allows 
them to "escape" the negative effects of competition, and gives them an additional monopoly profit. However, our analysis further reveals that, when the retail cost of store brands is not pronounced, i.e., $c_{s}<c_{s 2}$, the introduction of store brand actually deters the manufacturer to lease a "greener" version. This argument therefore contributes to a better understanding of the underlying dimensions of green design for manufacturers' brands when confronted with competition from store brands, and suggests that the manufacturer should take both the costs of product development and the competitive advantage of the retailer into consideration.

Third, from the implications on economic performance, the presence of store brands benefits the retailer, while it hurts the manufacturer. Our argument suggests that, if manufacturers intend to design for the environment with a price premium, the days of ignoring cannibalization problems from retailers' store brands are over. In particular, in 2000, store brands accounted for $20 \%$ of retail sales in the US market. This tendency has been particularly notable since 2007: The growth rate of store brands was $21 \%$, and created more than $\$ 10.5$ billion per year in annual sales [45]. In 2015, the total annual sales of store brands reached $\$ 118.4$ billion in the USA market [47]; this tendency is more prevalent in Europe, in which store brands in large market shares vary between $40 \%$ and $53 \%$ [45]. In addition, to incentivize the manufacturer to support Model S, we propose a two-part tariff contract.

\subsection{Limitations and Directions for Future Research}

This paper could be extended in the following ways. First, our models characterize store brands as traditional-type products with lower prices: This characterization is common in the literature on national brands vs. store brands (see, e.g., Nasser et al. [52], Li et al. [53], and Alan et al. [54]), but it does not reflect the actuality that the retailer could offer "me too" products that are green versions of store brands. This opens an interesting research direction: The potential incorporation of green design into store brands. Second, our channel structure is somewhat simplified and does not consider competition between national brands. Finally, it would be informative to empirically test our results in future research.

Author Contributions: X.Y. responded for finding motivation cases and writing; W.Z. contributed to model development, M.X. strengthen all results' interpretation. All authors have read and agreed to the published version of the manuscript.

Funding: The authors thank National Natural Science Foundation of China (71471024).

Conflicts of Interest: The authors declare no conflict of interest.

\section{Appendix A. Derivation of the Optimal Decisions}

\section{Appendix A.1. Derivation of the Optimal Decisions under Model B}

Plugging Equation (2) into the Equation (3) and solving the first-order condition yields $q_{n}^{B *}=\frac{\sigma_{1}-c_{n}-w_{n}}{2 \sigma_{1}}$.

After plugging $q_{n}^{B *}$, we can rewrite the manufacturer's profit as follows.

$$
\max _{w_{n}} \pi_{m}^{B}=w_{n}\left(\frac{\sigma_{1}-c_{n}-w_{n}}{2 \sigma_{1}}\right)-\frac{k\left(\sigma_{1}^{2}-1\right)}{2}
$$

By solving the first-order condition of $w_{n}$ and yields, $w_{n}^{B *}=\frac{\sigma_{1}-c_{n}}{2}$. Substituting $w_{n}^{B *}$ into $q_{n}^{B *}$, and Equations (3) and (4) provides the equilibrium outcomes in Table 1.

\section{Appendix A.2. Derivation of the Optimal Decisions under Model S}

Plugging (1) into the retailer's profit and solving the first-order condition yields $q_{n}^{S}=\frac{\sigma_{1}-\sigma_{2}-w_{n}-c_{n}+c_{S}}{2\left(\sigma_{1}-\sigma_{2}\right)}, q_{s}^{S}=\frac{c_{n} \sigma_{2}-c_{S} \sigma_{1}+\sigma_{2} w_{n}}{2 \sigma_{2}\left(\sigma_{1}-\sigma_{2}\right)}$. 
After plugging both optimal quantities into Equation (6) and we can rewrite the manufacturer's profit as follows.

$$
\max _{w_{n}} \pi_{m}^{S}=w_{n}\left(\frac{\sigma_{1}-\sigma_{2}-w_{n}-c_{n}+c_{s}}{2\left(\sigma_{1}-\sigma_{2}\right)}\right)-\frac{k\left(\sigma_{1}^{2}-1\right)}{2} .
$$

Solving the first-order condition of above equation and yields, $w_{n}^{S *}=\frac{c_{S}-c_{n}+\sigma_{1}-\sigma_{2}}{2}$. Substituting $w_{n}^{S_{*}^{*}}$ into $q_{n}^{S_{*}}, q_{s}^{S_{*}}$, and Equations (5) and (6) provides the equilibrium outcomes in Table 1.

\section{Appendix B. Proofs}

\section{Appendix B.1. Proof of Proposition 1}

To prove $w_{n}^{S *}<w_{n}^{B *}$, we have to show that $w_{n}^{S_{*}}-w_{n}^{B *}=\frac{c_{S}-c_{n}+\sigma_{1}-\sigma_{2}}{2}-\frac{\sigma_{1}-c_{n}}{2}=\frac{c_{S}-\sigma_{2}}{2}$. This is true for any $\underline{c}_{s}<c_{S}<\bar{c}_{s}$. That is to say, for any $\underline{c}_{s}<c_{s}<\bar{c}_{s}, w_{n}^{S *}<w_{n}^{B *}$ is always true.

\section{Appendix B.2. Proof of Proposition 2}

To prove $q_{n}^{S_{*}^{*}}>q_{n}^{B *}$, we have to show that $q_{n}^{S_{*}^{*}}-q_{n}^{B *}=\frac{c_{n} \sigma_{2}-\sigma_{1} c_{s}}{4\left(\sigma_{2}-\sigma_{1}\right) \sigma_{1}}$. We find that, if $c_{s}>c_{s 1}=\frac{c_{n} \sigma_{2}}{\sigma_{1}}$, then $q_{n}^{S *}>q_{n}^{B *}$. Comparing $c_{s 1}$ to $\underline{c}_{s}$, and $\bar{c}_{s}$, we further find that $\underline{c}_{s}<c_{s 1}<\bar{c}_{s}$. That is, we can conclude that, if $c_{s}>c_{s 1}=\frac{c_{n} \sigma_{2}}{\sigma_{1}}$, then $q_{n}^{S *}>q_{n}^{B *}$; otherwise, $c_{s}<c_{s 1}=\frac{c_{n} \sigma_{2}}{\sigma_{1}}$ then $q_{n}^{S *}<q_{n}^{B *}$.

Appendix B.3. Proof of Proposition 3

To prove $K^{S}>K^{B}$, we solve the following equation of $K^{S}-K^{B}=$ $\frac{\left(\sigma_{1}-\sigma_{2}\right)\left(c_{n}-c_{s}+\sigma_{2}-1\right)^{2}+\left(\sigma_{1}-c_{n}+c_{s}-\sigma_{2}\right)^{2}\left(\sigma_{2}-1\right)}{4\left(\sigma_{1}^{2}-1\right)\left(\sigma_{2}-1\right)\left(\sigma_{1}-\sigma_{2}\right)}-\frac{\sigma_{1}-c_{n}^{2}}{4 \sigma_{1}\left(1+\sigma_{1}\right)}$ and find that there is a threshold of $\underline{c}_{s}<c_{s 2}=\frac{c_{n}\left(2 \sigma_{1}-2 \sqrt{\left(1-\sigma_{2}\right) \sigma_{1}\left(\sigma_{1}-\sigma_{2}\right)}\right)}{2 \sigma_{1}}<\bar{c}_{s}$, above which $K^{S}>K^{B}$. That is to say, for any $c_{s}>c_{s 2}, K^{S}>K^{B}$ is always true.

Appendix B.4. Proof of Proposition 4

To prove $\pi_{m}^{S}<\pi_{m}^{B}$, we have to show that $\pi_{m}^{S *}-\pi_{m}^{B *}=\frac{\sigma_{1}\left(c_{n}-c_{s}-\sigma_{1}+\sigma_{2}\right)^{2}-\left(\sigma_{1}-\sigma_{2}\right)\left(c_{n}-\sigma_{1}\right)^{2}}{8 \sigma_{1}\left(\sigma_{1}-\sigma_{2}\right)}<0$. This is true for any $\underline{c}_{s}<c_{s 1}<\bar{c}_{s}$. That is to say, for any $\underline{c}_{s}<c_{s 1}<\bar{c}_{s}, \pi_{m}^{S}<\pi_{m}^{B}$ is always true.

Appendix B.5. Proof of Proposition 5

To prove $\pi_{r}^{S}>\pi_{r}^{B}$, we have to show that $\pi_{r}^{S}-\pi_{r}^{B}=$ $\frac{c_{n}^{2} \sigma_{2}^{2}-2 c_{n} c_{s} \sigma_{1} \sigma_{2}+4 c_{s}^{2} \sigma_{1}^{2}-3 c_{s}^{2} \sigma_{1} \sigma_{2}-6 c_{s} \sigma_{1}^{2} \sigma_{2}+6 c_{s} \sigma_{1} \sigma_{2}^{2}+3 \sigma_{1}^{2} \sigma_{2}^{2}-3 \sigma_{1} \sigma_{2}^{3}}{16 \sigma_{1} \sigma_{2}\left(\sigma_{1}-\sigma_{2}\right)}>0$. This is true for any $\underline{c}_{s}<c_{s 1}<\bar{c}_{s}$. That is to say, for any $\underline{c}_{s}<c_{s 1}<\bar{c}_{s}, \pi_{r}^{S}>\pi_{r}^{B}$ is always true.

\section{Appendix B.6. Proof of Proposition 6}

To prove $\pi_{t}^{S}>\pi_{t}^{B}$, we have to show that $\pi_{t}^{S}-\pi_{t}^{B}=$ $\frac{3 c_{n}^{2} \sigma_{2}^{2}-6 c_{n} c_{s} \sigma_{1} \sigma_{2}+4 c_{S}^{2} \sigma_{1}^{2}-c_{s}^{2} \sigma_{1} \sigma_{2}-2 c_{s} \sigma_{1}^{2} \sigma_{2}+2 c_{s} \sigma_{1} \sigma_{2}^{2}+\sigma_{1}^{2} \sigma_{2}^{2}-\sigma_{1} \sigma_{2}^{3}}{16 \sigma_{1} \sigma_{2}\left(\sigma_{1}-\sigma_{2}\right)}>0$. This is true for any $\underline{c}_{s}<c_{s 1}<\bar{c}_{s}$. That is to say, for any $\underline{c}_{s}<c_{s 1}<\bar{c}_{s}, \pi_{t}^{S}>\pi_{t}^{B}$ is always true. 
Appendix B.7. Proof of Proposition 7

Plugging (1) into (7) and solving the first-order condition yields $q_{n}^{S}=\frac{\sigma_{1}-\sigma_{2}-w_{n}-c_{n}+c_{S}}{2\left(\sigma_{1}-\sigma_{2}\right)}$, $q_{s}^{S}=\frac{c_{n} \sigma_{2}-c_{s} \sigma_{1}+\sigma_{2} w_{n}}{2 \sigma_{2}\left(\sigma_{1}-\sigma_{2}\right)}$.

After plugging both optimal quantities into Equation (8), we can rewrite the manufacturer's profit as follows.

$$
\max _{w_{n}} \pi_{m}^{S}=w_{n}\left(\frac{\sigma_{1}-\sigma_{2}-w_{n}-c_{n}+c_{s}}{2\left(\sigma_{1}-\sigma_{2}\right)}\right)-\frac{k\left(\sigma_{1}^{2}-1\right)}{2}+T .
$$

Solving the first-order condition of above equation yields, $w_{n}^{S_{*}}=\frac{\sigma_{1}-c_{n}}{2}$. While the constraint that ensures the retailer accepts the coordination contract offered by the manufacturer, we need to compare the retailer profits in Model $\mathrm{S}$ and Model B. That is, $\pi_{r}^{S}-\pi_{r}^{B}=$ $\frac{c_{n}^{2} \sigma_{2}^{2}-2 c_{n} c_{s} \sigma_{1} \sigma_{2}+4 c_{s}^{2} \sigma_{1}^{2}-3 c_{s}^{2} \sigma_{1} \sigma_{2}-6 c_{s} \sigma_{1}^{2} \sigma_{2}+6 c_{s} \sigma_{1} \sigma_{2}^{2}+3 \sigma_{1}^{2} \sigma_{2}^{2}-3 \sigma_{1} \sigma_{2}^{3}}{16 \sigma_{1} \sigma_{2}\left(\sigma_{1}-\sigma_{2}\right)}-T \geq 0$ then we can obtain that there is a threshold of $\bar{T}=\frac{\left[\begin{array}{l}c_{n}^{2} \sigma_{2}^{2}-2 c_{n} c_{s} \sigma_{1} \sigma_{2}+4 c_{s}^{2} \sigma_{1}^{2}-3 c_{s}^{2} \sigma_{1} \sigma_{2} \\ -6 c_{s} \sigma_{1}^{2} \sigma_{2}+6 c_{s} \sigma_{1} \sigma_{2}^{2}+3 \sigma_{1}^{2} \sigma_{2}^{2}-3 \sigma_{1} \sigma_{2}^{3}\end{array}\right]}{16 \sigma_{1} \sigma_{2}\left(\sigma_{1}-\sigma_{2}\right)}$, below which $\pi_{r}^{S}>\pi_{r}^{B}$. That is to say, for any $T^{S *} \leq \bar{T}$, the retailer's profit in Model S is not less than that in Model B. That is, if the manufacturer acts as the Stackelberg leader and the sponsors of the coordination contract, the manufacturer's optimal response would be $T^{S *}=\bar{T}=\frac{\left[\begin{array}{c}c_{n}^{2} \sigma_{2}^{2}-2 c_{n} c_{s} \sigma_{1} \sigma_{2}+4 c_{s}^{2} \sigma_{1}^{2}-3 c_{s}^{2} \sigma_{1} \sigma_{2} \\ -6 c_{s} \sigma_{1}^{2} \sigma_{2}+6 c_{s} \sigma_{1} \sigma_{2}^{2}+3 \sigma_{1}^{2} \sigma_{2}^{2}-3 \sigma_{1} \sigma_{2}^{3}\end{array}\right]}{16 \sigma_{1} \sigma_{2}\left(\sigma_{1}-\sigma_{2}\right)}$.

\section{References}

1. Agency, U.S.E.P. Greenhouse Gases Equivalencies Calculator-Calculations and References. Available online: https://www.epa.gov/energy/greenhouse-gases-equivalencies-calculator-calculations-andreferences2017 (accessed on 18 December 2019).

2. Steenkamp, J.-B.E.M. Global Versus Local Consumer Culture: Theory, Measurement, and Future Research Directions. J. Intern. Mark. 2019, 27, 1-19. [CrossRef]

3. Chen, Y.-S.; Lin, C.-Y.; Weng, C.-S. The Influence of Environmental Friendliness on Green Trust: The Mediation Effects of Green Satisfaction and Green Perceived Quality. Sustainability 2015, 7, 10135-11052. [CrossRef]

4. Eurobarometer. Attitudes of European Citizens towards the Environment. 2008. Available online: http: //www.europafacile.net/Formulari/POLITICHE/Ambiente/report_ebenv_2005_04_22_en.pdf (accessed on 18 December 2019).

5. Daily, C. Chinese Gov't a Green Consumer. 2019. Available online: http://www.chinadaily.com.cn/china/ 2007-01/02/content_773374.htm (accessed on 18 December 2019).

6. Martin-Rios, C. Innovative and Sustainable Business Models and Practices. 2020. Available online: https: //www.mdpi.com/journal/sustainability/special_issues/service_innovation (accessed on 29 January 2020).

7. Keoleian, G.A.; Curran, M.A. Life cycle design framework and demonstration projects. In Proceedings of the Conference: 21, Environmental Protection Agency (EPA) annual Risk Reduction Engineering Laboratory Research Symposium, Cincinnati, OH, USA, 4-6 April 1995; EPA: Cincinnati, OH, USA, 1995; pp. 27-28.

8. Yang, J.; Su, J.; Song, L. Selection of Manufacturing Enterprise Innovation Design Project Based on Consumer's Green Preferences. Sustainability 2019, 11, 1375. [CrossRef]

9. Chambers, A. SWEPCO makes first factory EV pickup. Power Eng. 1997, 101, 10.

10. Ottman, J.A.; Miller, D.M. Green Marketing: Opportunity for Innovation. J. Sustain. Prod. Des. 1998, 10, 60.

11. Heyes, A.; Kapur, S.; Kennedy, P.W.; Martin, S.; Maxwell, J.W. But What Does It Mean? Competition between Products Carrying Alternative Green Labels When Consumers Are Active Acquirers of Information. J. Assoc. Environ. Resource Econ. 2020, 7, 243-277.

12. Ginsburg, J. Once is not enough. Bus. Week 2001, 16, 128-129. 
13. Wright, G.H.; Pujari, D.; Peattie, K. Green and competitive: influences on environmental new product development performance. J. Bus. Res. 2003, 56, 657-671.

14. Reinhardt, F.L. Environmental Product Differentiation: Implications For Corporate Strategy. Calif. Manag. Rev. 1998, 40, 43-73. [CrossRef]

15. Guo, S.; Choi, T.-M.; Shen, B. Green product development under competition: A study of the fashion apparel industry. Eur. J. Oper. Res. 2020, 280, 523-538. [CrossRef]

16. Olsen, M.C.; Slotegraaf, R.J.; Chandukala, S.R. Green Claims and Message Frames: How Green New Products Change Brand Attitude. J. Mark. 2014, 78, 119-137. [CrossRef]

17. Steenkamp, J.-B.E.M.; Van Heerde, H.J.; Geyskens, I. What Makes Consumers Willing to Pay a Price Premium for National Brands over Private Labels? J. Mark. Res. 2010, 47, 1011-1024. [CrossRef]

18. Hassan, D.; Monier-Dilhan, S. National brands and store brands: Competition through public quality labels. Agribusiness 2006, 22, 21-30. [CrossRef]

19. Liu, R.L.; Sprott, D.E.; Spangenberg, E.R.; Czellar, S.; Voss, K.E. Consumer preference for national vs. private brands: The influence of brand engagement and self-concept threat. J. Retail. Consum. Serv. 2018, 41, 90-100. [CrossRef]

20. Mieres, C.G.; María, A.; Martín, D.; Antonio, J. and Gutiérrez, T. Antecedents of the difference in perceived risk between store brands and national brands. Eur. J. Mark. 2006, 40, 61-82. [CrossRef]

21. Chen, D.; Ignatius, J.; Sun, D.; Goh, M.; Zhan, S. Pricing and equity in cross-regional green supply chains. Eur. J. Oper. Res. 2020, 280, 970-987. [CrossRef]

22. Liao, B.; Yano, C.A.; Trivedi, M. Optimizing Store-Brand Quality: Impact of Choice of Producer and Channel Price Leadership. Prod. Oper. Manag. 2020, 29, 118-137. [CrossRef]

23. Huang, Z.; Feng, T. Money-back guarantee and pricing decision with retailer's store brand. J. Retail. Consum. Serv. 2020, 52, 101897. [CrossRef]

24. Brat, I.; Cordeiro, A. Store Brands Squeeze Big Food Firms: After Profiting from Higher Prices, conAgra and Other Makers are Rethinking Strategy as Volume Falls. 2009. Available online: https://www.wsj.com/articles/ SB123807261203947597 (accessed on 18 December 2019).

25. Du, S.; Tang, W.; Zhao, J. and Nie T. Sell to whom? Firm's green production in competition facing market segmentation. Ann. Oper. Res. 2018, 270, 125-154. [CrossRef]

26. Pritchard, M.; Wilson, T. Building corporate reputation through consumer responses to green new products. J. Brand Manag. 2018, 25, 38-52. [CrossRef]

27. Wang, X.Q.; Yuen, K.F.; Wong, Y.D.; Teo, C.C. It is green, but is it fair? Investigating consumers' fairness perception of green service offerings. J. Clean. Prod. 2018, 181, 235-248. [CrossRef]

28. Chen, X.; Wang, X.J.; Zhou, M.M. Firms' green R\&D cooperation behaviour in a supply chain: Technological spillover, power and coordination. Intern. J. Prod. Econ. 2019, 218, 118-134.

29. Laroche, M.; Bergeron, J.; Barbaro-Forleo, G. Targeting Consumers Who Are Willing to Pay More for Environmentally Friendly Products. J. Consum. Mark. 2001, 18, 503-520. [CrossRef]

30. Morrison, P.S.; Beer, B. Consumption and Environmental Awareness: Demographics of the European Experience. 2017. Available online: https://link.springer.com/chapter/10.1007/978-981-10-0099-7_5 (accessed on 18 December 2019).

31. Kai, C.; Deng, T. Research on the Green Purchase Intentions from the Perspective of Product Knowledge. Sustainability 2016, 8, 943.

32. Anning-Dorson, T. Complementarity of capabilities across cultures Innovation, customer involvement, and competitiveness of service firms across India and the UK. Cross Cult. Strateg. Manag. 2019, 26, 567-585. [CrossRef]

33. Chen, C.L. Design for the environment: A quality-based model for green product development. Manag. Sci. 2001, 47, 250-263. [CrossRef]

34. Zhang, L.; Wang, J.; You, J. Consumer environmental awareness and channel coordination with two substitutable products. Eur. J. Oper. Res. 2015, 241, 63-73. [CrossRef]

35. Gómez, M. Manufacturer's characteristics that determine the choice of producing store brands. Eur. J. Mark. 2008, 42, 154-177. [CrossRef]

36. Ailawadi, K.L.; Pauwels, K.; Steenkamp, J.-B.E.M. Private-Label Use and Store Loyalty. J. Market. 2008, 72, 19-30. [CrossRef] 
37. Rubio, N.; Oubiña, J.; Villaseñor, N. Brand awareness-Brand quality inference and consumer's risk perception in store brands of food products. Food Qual. Preference 2014, 32, 289-298. [CrossRef]

38. Yin, S.; Ray, S.; Gurnani, H.; Animesh, A. Durable Products with Multiple Used Goods Markets: Product Upgrade and Retail Pricing Implications. Mark. Sci. 2010, 29, 540-560. [CrossRef]

39. Agrawal, V.V.; Uelkue, S. The Role of Modular Upgradability as a Green Design Strategy. MESom-Manuf. Serv. Oper. Manag. 2013, 15, 640-648.

40. Qian, Z.; Chai, J.; Li, H.; Yan, W.; Chen, H. Implications of product upgrading confronting supplier remanufacturing. Int. J. Prod. Res. 2019, 57, 1-23. [CrossRef]

41. Yan, W.; Xiong, Y.; Xiong, Z.; Guo, N. Bricks vs. clicks: Which is better for marketing remanufactured products? Eur. J. Oper. Res. 2015, 242, 434-444. [CrossRef]

42. Sayman, S.; Hoch, S.J.; Raju, J.S. Positioning of store brands. Mark. Sci. 2002, 21, 378-397. [CrossRef]

43. Amrouche, N.; Yan, R. Aggressive or partnership strategy: Which choice is better for the national brand? Intern. J. Prod. Econ. 2015, 166, 50-63. [CrossRef]

44. Karray, S.; Martin-Herran, G. Fighting store brands through the strategic timing of pricing and advertising decisions. Eur. J. Oper. Res. 2019, 275, 635-647. [CrossRef]

45. Ru, J.; Shi, R.; Zhang, J. Does a Store Brand Always Hurt the Manufacturer of a Competing National Brand? Prod. Oper. Manag. 2015, 24, 272-286. [CrossRef]

46. Atasu, A.; Sarvary, M.; Van Wassenhove, L.N. Remanufacturing as a Marketing Strategy. Manag. Sci. 2008, 54, 1731-1746. [CrossRef]

47. (PLMA), P.L.M.A. Store Brands Keep on Growing. Available online: https://plma.com/storeBrands/ marketprofile2016.html2019 (accessed on 18 December 2019).

48. Hong, Z.; Guo, X. Green product supply chain contracts considering environmental responsibilities. Omega 2019, 83, 155-166. [CrossRef]

49. Swami, S.; Shah, J. Channel coordination in green supply chain management. J. Oper. Res. Soc. 2013, 64, 336-351. [CrossRef]

50. Xu, J.; Chen, Y.; Bai, Q. A two-echelon sustainable supply chain coordination under cap-and-trade regulation. J. Clean. Prod. 2016, 135, 42-56. [CrossRef]

51. Arrow, K.J. Economic Welfare and the Allocation of Resources for Invention. In The Rate of Direction of Inventive Activity: Economic And Social Factors; Princeton University Press: Princeton, NJ, USA, 1962; pp. 609-626.

52. Nasser, S.; Turcic, D.; Narasimhan, C. National Brand's Response to Store Brands: Throw In the Towel or Fight Back? Mark. Sci. 2013, 32, 591-608. [CrossRef]

53. Li, W.; Chen, J.; Chen, B. Supply chain coordination with customer returns and retailer's store brand product. Intern. J. Prod. Econ. 2018, 203, 69-82. [CrossRef]

54. Alan, Y.; Kurtuluş, M.; Wang, C. The Role of Store Brand Spillover in a Retailer's Category Management Strategy. Manuf. Serv. Oper. Manag. 2019, 21, 620-635. [CrossRef] 